\title{
ALTERIDADE E ARQUÉTIPOS EM SOLARIS DE STANISLAW LEM
}

\author{
Alterity and Archetypes in Stanistaw Lem's "Solaris"
}

\author{
Adriano Luís FONSACA \\ Universidade Federal do Paraná \\ fonsaca.adriano@gmail.com \\ https://orcid.org/0000-0002-5158-2261
}

RESUMO: O tema da alteridade e dos arquétipos estão presentes no romance Solaris de Stanisław Lem. O dado artigo apresenta e discute a ficção científica Solaris com o auxílio dos pensamentos de Jung e das ideias de alteridade, sobretudo de autores como Goffman. Num primeiro momento, obteve-se, como resultado da observação, a percepção do modo como os arquétipos estão inseridos na obra e como o "eu" do protagonista é interpretado pelas demais mentes pensantes presentes na narrativa. Solaris é apresentado através de um olhar interpretativo enviesado pela psicologia junguiana, pensando em trazer novas ideias e possibilidades para a pesquisa da literatura polonesa. Olhar esse que, ao menos nos trabalhos realizados no Brasil, ainda não foi explorado. Apesar da fama mundial de Lem, sua obra ainda é pouco pesquisada em nosso país. Mesmo, talvez, sendo a mais pesquisada da literatura polonesa mundialmente. PALAVRAS-CHAVE: Literatura Polonesa; Arquétipos; Lem.

\begin{abstract}
The theme of otherness and archetypes are present in the Stanisław Lem's novel Solaris. The article presents and discusses the science fiction Solaris with the help of Jung's thoughts and ideas of otherness, especially by authors like Goffman. At first, it was obtained, as a result of observation, the perception of how the archetypes are inserted in the work and how the protagonist's "I" is interpreted by other thinking minds. Solaris is presented through an interpretive look by Jungian psychology, thinking of bringing new ideas and possibilities to the research of Polish literature. A look that, at least in the works carried out in Brazil, has not yet been explored. Despite Lem's worldwide fame, his work is still little researched in our country. Even though, perhaps, it is the most searched author of Polish literature worldwide. KEYWORDS: Polish Literature; Archetypes; Lem.
\end{abstract}




\section{INTRODUÇÃO}

Às $19 \mathrm{~h}$ do horário de bordo, passando pelos que estavam em volta do poço, desci pelos degraus de metal para o interior da cápsula, lá dentro, mal havia espaço para levantar os cotovelos. Depois que liguei a conexão ao tubo que saía da parede, minha roupa espacial inflou e, a partir de então, eu não consegui mais executar o menor movimento (LEM, 2017, p. 14).

A ficção científica se encarrega de trazer à luz muitas possibilidades ou ideias da ciência que, muitas vezes, acabam ficando somente no imaginário humano por serem, atualmente, inalcançáveis. É através desse meio que o autor polonês Stanisław Lem reflete o íntimo das pessoas em seu romance. Lem também aproveita para falar de situações opressivas onde o ser humano não tem controle ou entende bem o que acontece ao seu redor. Esse não entendimento acarreta em uma total inércia ou inabilidade das pessoas lidarem com certas situações que acontecem em suas vidas. Podemos enxergar parte dessas situações, das quais Lem se refere, como sendo uma pincelada no sofrimento da Polônia e do povo judeu com o holocausto, afinal o autor possui origens judaicas e quase não saiu vivo desse período de opressão.

Temos então a alteridade e os arquétipos junguianos, temas centrais presentes aqui para discutir o romance Solaris. Logo após contextualizações, esses os conceitos são apresentados e a obra refletida a partir deles. A discussão apresenta alguns dos paradigmas da literatura de ficção científica bem como fala da estrutura arquetípica que está presente no livro Solaris. Neste trabalho foi utilizada a versão da obra Solaris (LEM, 2017), traduzida por Eneida Favre diretamente do polonês em 2017.

Como foco teórico, temos então:

Analisar, sob o escopo da psicologia junguiana e da ideia da alteridade, a ficção científica Solaris do autor polonês Stanisław Lem;

Refletir o viés psicológico da obra;

Trazer à tona em quais figuras e em quais momentos centrais da narrativa alguns arquétipos se manifestam. 


\section{FUNDAMENTAÇÃO TEÓRICA}

\section{O autor e a obra}

Stanisław Lem foi um escritor polonês de origens judaicas, trabalhou principalmente com ficção científica, filosofia e sátira. Nascido em 1921 na cidade de Lwów da Segunda República Polonesa e atual Lviv, Ucrânia. Sua vida foi conturbada pelos períodos de ocupações soviéticas e nazistas na região. Em dado momento chegou a ter que recorrer a documentos falsos para trabalhar como mecânico de automóveis e soldador, enquanto participava ativamente da resistência à ocupação nazista. Seu pai era médico e um polonês étnico e sua mãe, dona de casa, de origem polonesa e alemã. Na juventude inicia o curso de medicina na Universidade de Lviv, mas só continua seus estudos posteriormente na Universidade Jaguelônica e devido a insistência de seu pai. Por recusar-se a aceitar o lysenkoismo, uma pseudociência em voga na época que exaltava a herança de caracteres adquiridos e se justificava através da distorção do processo científico, acaba por fracassar nos exames finais (LEM about himself In: Lem.pl. Stanisław Lem - The Official Site, c2016).

Lem entrou para a literatura em 1946 como poeta e seu primeiro romance de ficção científica, Człowiek z Marsa, começou a ser publicado no periódico Nowy Świat Przygód (Novo Mundo de Aventuras). Nos anos seguintes, Lem publicou poemas, contos e ensaios científicos. Apesar de que, durante a era do stalinismo, todo seu trabalho tinha de ser diretamente aprovado pelo regime antes de ser publicado. Em 1951 Lem publica seu primeiro livro completo, Astronauci; uma encomenda de ficção científica para jovens e adolescentes na qual o autor teve que incluir referências ao sistema soviético. Posteriormente, Lem critica seu próprio romance como simplista, mas mesmo assim, a publicação o motivou a tornar-se um escritor em tempo integral (HOSCH in Encyclopedia Britannica).

Após 1956 o autor torna-se mais producente e até 1968, escreve 17 livros. Suas obras foram amplamente traduzidas no exterior. Em 1957 publica seu primeiro livro de não-ficção, Dialogi; este e Summa Technologiae (1964) são seus textos filosóficos mais famosos. Ao longo do tempo, Lem gradualmente larga a ficção em favor de crítica social, filosofia e futurologia (HOSCH in Encyclopedia Britannica).

Com Cyberiada (1967), uma série de contos ambientados num universo habitado por máquinas, Lem adquire grande notoriedade internacional. Seus romances mais conhecidos incluem Solaris (1961), A Voz do Mestre (1968) e Fiasco (1986), todos com 
um tema recorrente: o de que seriam em vão os esforços para a humanidade compreender uma sociedade alienígena, pois ela não compreende direito a si própria (LEM about himself In: Lem.pl. Stanisław Lem - The Official Site, c2016).

Solaris foi inicialmente adaptado em 1968 pelo cinema russo, mas é na versão de 1972 de Andrei Tarkovsky que ganha notoriedade e o prêmio especial do júri no Festival de Cannes. Em 2002, Steven Soderbergh dirigiu a adaptação hollywoodiana estrelando George Clooney. Solaris também foi adaptado para óperas, teatro, audiobook e teve versão dramatizada em rádio. Após essa jornada de vida, Stanisław Lem falece na cidade de Cracóvia em março de 2006.

A princípio a trama de Solaris narra a história de um grupo de cientistas que estão em uma estação espacial que orbita um planeta alienígena. Todavia, o planeta não é um mero corpo celeste, pois possui um oceano que parece ter vida própria segundo pesquisas prévias (MARINO, 2017).

Os cientistas não estão sozinhos na estação espacial, pois pessoas importantes de suas vidas, que deveriam estar na Terra ou até mortas, os seguem por onde quer que estejam. Essas pessoas, ou seres, são chamados de hóspedes. Todo a trama é narrada em primeira pessoa, sobre o ponto de vista do psiquiatra e protagonista Kris Kelvin, através de seu olhar que tomamos conhecimento da trama. Descobrimos aquele novo mundo sobre a visão e interpretação das experiências de Kris, bem como de vários relatórios científicos que o herói lê durante sua jornada.

No andamento da narrativa várias questões surgem, temos a impressão que não são os cientistas que estudam Solaris, mas eles que são "estudados" pelo oceano vivo; isso segundo o ponto de vista de algumas pesquisas apresentadas na história e o total desconcerto de um Kelvin mergulhado em sua própria ignorância quando narra, por exemplo, "aqui, para compreender qualquer verdade, é preciso se retirar, se afastar a uma enorme distância" (LEM, 2017, p. 185).

Também é possível, em um primeiro momento, interpretar que os hóspedes são tentativas do oceano de compreender a mente humana. Todavia, com um olhar mais direcionado, pode-se encontrar alguma reflexão psicológica mais subjetiva e arquetípica, a qual seria exatamente o tema central da obra? É o que tentar-se-á refletir.

\section{Algumas teorias para interpretar Solaris}

Esse "completo fracasso" humano em compreender o que se passa em Solaris, que o resumo descreveu, nos arremete a uma questão, básica talvez, mas que sem ela não conseguiríamos nos centrar enquanto acompanhamos a jornada de Kris Kelvin: a questão 
da alteridade ${ }^{1}$. Nesse ponto, uma série de autores que se seguem conseguem convergir.

O filósofo e sociólogo polonês Zygmunt Bauman nos diz, em seus trabalhos, sobre a "liquidez" das relações sociais e interpessoais que acomete a sociedade intensificando-se a partir do século XX. Ele nos diz que na pós-modernidade a identidade humana também não é durável e ela ser "bem costurada já é uma vantagem; crescente, e de maneira cada vez mais clara, ela se torna uma responsabilidade. O eixo da estratégia de vida pósmoderna não é fazer a identidade deter-se - mas evitar que se fixe" (BAUMAN, 1997, p. 114). Kris Kelvin, não só por apresentar as ideias de uma literatura dos anos sessenta do século XX, mas também por refletir o futuro da nossa humanidade pós-moderna que está no crescente aumento de velocidade das interações das vidas individuais e do sistema da sociedade como um todo, exemplifica um indivíduo fulminado por essa liquidez. Perdido e traumatizado em seu âmago pelo suicídio de sua amada, ou ex-amada, Harey, Kris já chega em Solaris completamente fragmentado e fragilizado psicologicamente, mesmo tendo um objetivo bem definido; como psiquiatra, deve analisar o que está acontecendo na estação e pesquisar a relação disso com o oceano supostamente vivo que existe em Solaris.

No decorrer da exploração de Kris à estação, ele se depara com várias teorias científicas da solarística, a ciência desse mundo ficcional que estuda o planeta Solaris, encontradas em livros e relatórios. Esses textos que o psiquiatra encontra durante a narrativa, mostra que grandes explorações outrora foram realizadas ao planeta extraterrestre, mas como os resultados eram lentos e, em determinado momento, quase nulos, o ritmo diminui. Bauman dialoga também com a ficção ao dizer que

as escalas são acampamentos, não domicílios. (...) Só as mais superficiais das raízes, se tanto, são lançadas. (...) Acima de tudo, não há nenhum comprometimento do futuro, nenhuma incursão em obrigações de longo prazo, nenhuma admissão de alguma coisa que aconteça para se ligar com o amanhã (BAUMAN, 1997, p. 115),

pois na narrativa é explicado que, num primeiro momento, a humanidade ficou extremamente empolgada com a descoberta de Solaris e muito foi investido para se explorar e descobrir esse novo mundo. Todavia, com o passar dos anos, por nenhuma grande novi-

\footnotetext{
${ }^{1}$ Substantivo feminino. Caráter ou estado do que é diferente, distinto, que é outro. Que se opõe à identidade, ao que é próprio e particular; que enxerga o outro, como um ser distinto, diferente. [Filosofia] Circunstância, condição ou característica que se desenvolve por relações de diferença, de contraste. Etimologia (origem da palavra alteridade). Do francês altérité, "mudança"; pelo latim alteritas.atis (DICIO, 2019).
} 
dade ter sido identificada, Solaris é quase esquecido e vira uma simples nota de rodapé em noticiários por causa da falta de resultados mais imediatos pelos quais as pessoas esperavam. A sociedade, afinal, não se compromete com futuro algum e só se preocupa com um agora que é totalmente efêmero. $\mathrm{O}$ amanhã não importa mais.

O que está fora do lugar, da ordem vigente, é impuro para quem está estabelecido em um local. Nesse ponto, o turista, estrangeiro ou "outsider" que está fora de seu mundo comum, é visto como um "agente poluidor", como um ser que deve ser retirado desse espaço ou não deveria estar ali (BAUMAN, 1997, p. 14). Para corroborar com Bauman e pensarmos agora em Kris sendo a figura do "outsider" a sua cultura, podermos ver, por exemplo, a pesquisa de Nobert Elias que mostrou empiricamente como membros de uma determinada comunidade se fecham em si e que, quem vem de fora, não tem espaço ou se faz entendido lá, pois "os grupos estabelecidos veem seu poder superior como um sinal de valor humano mais elevado" (ELIAS, 2000, p. 28) onde a inferioridade de poder é também vista como uma inferioridade humana (ELIAS, 2000, p. 28). No caso de Solaris, o oceano vivo exerce a sua pressão indiretamente e são os humanos que não conseguem entender suas peculiaridades. Apesar de que, com a chegada de um novo cientista a estação, podemos notar como quem já estava ali se fecha para Kris, o outsider daquela diminuta comunidade. De todo o modo, os cientistas e Kris são ambos outsiders perante Solaris.

Snaut e Sartorius, os outros cientistas que estão na estação, "interpretam papéis" perante as adversidades e fingem verdades para psiquiatra outsider recém-chegado. Um pouco mais amigável, mas desconfiado, Snaut trava alguns diálogos com Kris Kelvin, mas sempre mantendo a pose de cientista e uma distância do novato. Após entender que o psiquiatra não é um hóspede, se abre mais e explica algumas situações que ocorreram nas pesquisas e na estação com esses hóspedes. Sartorius aparentemente é mais compenetrado em suas pesquisas e não liga tanto par ao fenômeno; finge ser o cientista perfeito. Todavia, pela perseguição que os hóspedes exercem sobre os humanos verdadeiros, sentimos que todos ali estão interpretando papéis ao invés de desempenharem suas tarefas ou serem eles mesmo. O próprio Kelvin, em praticamente toda a obra, não demonstra claramente como exerce sua atividade de psiquiatra, mesmo tentando manter sempre a pose ou até travar algum diálogo mais profundo com seus colegas de trabalho. Para ajudar no discutido, Erving Goffman, em sua pesquisa sobre as representações humanas na vida cotidiana, nos diz que “(...) assim os indivíduos se encontram muitas vezes em face do dilema expressão versus ação. Aqueles que têm tempo e talento para desempenhar bem uma tarefa não podem, por este motivo, ter tempo para mostrar que estão representando 
bem" (GOFFMAN, 1996, p. 39). Claramente notamos que os cientistas da estação estão em dilemas, seja em como lidar uns com os outros ou como lidar com os hóspedes que coabitam com eles.

Para Carl Gustav Jung, arquétipo é uma efígie apriorística encravada profundamente no inconsciente coletivo ${ }^{2}$ da humanidade, projetando-se em diversos meandros da vida, como em sonhos e até mesmo nas artes. Ele explica que "no concernente ao conteúdo do inconsciente coletivo, estamos tratando de tipos arcaicos - ou melhor - primordiais, isto é, de imagens universais que existiram desde os tempos mais remotos" (JUNG, 2000, p. 16). Essas imagens universais estariam circundando todas as esferas do humano, culminando em seu desenrolar nas narrativas ficcionais criadas pelos mesmos seres humanos.

Ainda sobre o tema, C. G. Jung (2000) esclarece sobre onde encontramos as representações arquetípicas. A partir de seu conceito, que advém da observação reiterada de que os mitos encerram temas bem definidos que reaparecem sempre e por toda parte, como em contos da literatura universal, percebemos que é possível encontramos esses mesmos temas também nas fantasias, nos sonhos, nas ideais delirantes e nas ilusões dos indivíduos. A essas imagens e correspondências típicas, ele denominou representações arquetípicas. Quanto mais nítidas, mais essas representações são acompanhadas de tonalidades afetivas vividas. Elas nos impressionam, nos influenciam, nos fascinam. E tudo têm sua origem no arquétipo que, em si mesmo, escapa à representação, forma preexistente e inconsciente que parece fazer parte da estrutura psíquica herdada e pode, portanto, manifestar-se espontaneamente por toda parte.

Os arquétipos a serem descobertos e assimilados são precisamente aqueles que inspiraram, nos anais da cultura humana, as imagens básicas dos rituais, da mitologia e das visões. Esses "seres eternos do sonho" não devem ser confundidos com as figuras simbólicas, modificadas individualmente, que surgem num pesadelo ou na insanidade mental do indivíduo ainda atormentado. Parafraseando Campbell (2007, p. 27), o sonho é o mito personalizado e o mito é o sonho despersonalizado; o mito e o sonho simbolizam,

\footnotetext{
${ }^{2}$ Jung diz que "é o mundo da mente primitiva que se mantém profundamente inconsciente enquanto tudo corre bem na vida, mas que emerge dessa profundeza assim que algo de funesto se apresente à consciência. A esta camada impessoal da alma dei o nome de inconsciente coletivo. É "coletivo" porque não se trata de nada que tenha sido adquirido pessoalmente. É como que o funcionamento da estrutura herdada do cérebro, a qual em seus traços gerais é a mesma em todos os seres humanos, e de certo modo até mesmo em todos os mamíferos. O cérebro herdado é o resultado da vida de nossos antepassados. Consta dos sedimentos estruturais ou das correspondências àquelas atividades psíquicas, que inúmeras vezes foram repetidas na vida de nossos antepassados. Em contrapartida, constitui também o tipo existente a priori e aquilo que desencadeia a atividade correspondente. (JUNG, 1995, p. 106).
} 
da mesma maneira geral, a dinâmica da psique. Mas, nos sonhos, as formas são distorcidas pelos problemas particulares do sonhador, ao passo que, nos mitos, os problemas e soluções apresentados são válidos diretamente para toda a humanidade.

Aqui podemos dialogar entre Jung e o estruturalista russo Vladimir Propp, que fala da padronização estrutural existente em contos. Para o fundador da psicologia analítica, esse padrão pode ser mais relativo do que para Propp. Apesar dos arquétipos junguianos encontrados em toda literatura universal terem seus traços gerais e repetitivos, o que se pode fazer com esses aparentes padrões é encaixar acontecimentos mitológicos, reais ou ficcionais em uma forma (antigo fôrma). A combinação das funções, para Propp (2006), ou imagens arquetípicas (para Jung) pode ser tão arbitrária dentro de um conjunto de fatores psicológicos e sociais ao ponto de não ser insolúvel. Em suas reflexões, Jung (1994, p. 352) já dizia que é muito comum o mal-entendido de considerar o arquétipo como algo que possui um conteúdo determinado; em outros termos, faz-se dele uma espécie de "representação" inconsciente, se assim se pode dizer. É necessário sublinhar o fato de que os arquétipos não têm conteúdo determinado; eles só são determinados em sua forma e assim mesmo em grau limitado. Uma imagem primordial só tem um conteúdo determinado a partir do momento em que se torna consciente e é, portanto, preenchida pelo material da experiência consciente. Poder-se-ia talvez comparar sua forma ao sistema axial de um cristal que prefigura, de algum modo, a estrutura cristalina na água-mãe, se bem que não tenha por si mesmo qualquer existência material. Esta só se verifica quando os íons e moléculas se agrupam de uma suposta maneira. O arquétipo em si mesmo é vazio; é um elemento puramente formal, apenas uma facultas praeformandi (possibilidade de pré-formação), forma de representação dada a priori.

Tendo em vista o dito até agora, presenciamos em Solaris uma obra narrada em primeira pessoa, introspectiva e que versa sobre a alteridade humana e suas relações falhas onde nós chegamos ao ponto de nunca sermos nós mesmos e tão somente interpretamos papéis um para com os outros. Numa tentativa falha de entendermos um suposto oceano vivo, se quer conseguimos compreendermo-nos mutuamente. Notamos também como os arquétipos e uma estrutura arcaica mitológica podem estar presentes em Solaris e, para identificar tal, mais um pouco de explanações se faz necessária.

\section{APRESENTAÇÃO DOS RESULTADOS/REFLEXÕES}

Foi possível perceber que a trama de Solaris versa sobre como os humanos buscam entender o que está fora de si, mas não entendem sequer seus próprios sentimentos e 
suas relações com os outros, ou seja, temos uma importante reflexão de alteridade como proposta principal da narrativa. Em entrevista, a tradutora de Solaris para o português, Eneida Favre, nos deixa claro o posto acima:

Para mim o eixo principal do livro é colocado pelo personagem de Kelvin, quando ele conta que, certa vez, Veubeke, um diretor do instituto de solarística disse: "Como vocês vão se comunicar com um oceano, se não conseguem fazer isso uns com os outros? " Essa frase encerra a meu ver todas as tramas ocorrentes no livro: a busca desenfreada por entender o que está fora de nós, quando não conseguimos compreender os que vivem a nosso lado e nem entrar em contato profundo com os seus e os nossos próprios sentimentos e processos interiores (não é à toa que o protagonista é um psicólogo). Então, vejo Solaris como um questionamento da efetividade dessa busca em compreender o que é alienígena, sem antes, ou ao menos concomitantemente, tentar se aprofundar no âmago do espírito e do intelecto humano. (GRAMONSKI, 2019).

Se a teoria junguiana se tornar então outro filtro teórico para refletirmos Solaris, em um primeiro momento, pode-se chegar ao seguinte pressuposto: a relação de alteridade do oceano para com os humanos pode simbolizar o inconsciente coletivo, pois segundo Jung, o inconsciente "sabe tudo, pode tudo ou aprende tudo". Para Jung (1995), o inconsciente é a camada mais profunda da psique humana e é composto por materiais herdados; lá residem traços funcionais, algo como imagens virtuais, que seriam comuns a todos os seres humanos. $\mathrm{O}$ inconsciente coletivo também pode ser compreendido como uma estrutura composta por arquétipos cujas influências se propagam para além da psique humana.

Se o oceano pode acabar por ser compreendido como uma metáfora para o inconsciente coletivo, os hóspedes poderiam ser interpretados como a materialização de arquétipos relacionados aos personagens, em especial eles seriam a sombra de seus "progenitores". Em entrevista, a própria tradutora tem essa impressão ao dizer que “os hóspedes eram 'os pesadelos', os segredos mais profundos dos personagens, relacionamentos nos quais experimentaram algum tipo de sofrimento e que não foram bem resolvidos" (GRAMONSKI, 2019).

A materialização do pesadelo de Kris Kelvin, na figura de sua falecida companheira Harey, que é a manifestação de seus próprios medos e angústias, pode ser percebida também como uma materialização da imagem simbólica do arquétipo da sombra nele. A obra demonstra essa relação de dependência de Kris com Harey, pois o protagonista 
sucumbe a seus próprios medos da mesma forma que um herói trágico muitas vezes sucumbe a sua própria sombra ou, como diriam os gregos na antiguidade, sucumbe ao destino.

Como já dito, aparentemente todos os hóspedes que aparecem em Solaris seriam as sombras de seus respectivos anfitriões, mas vale nos atentarmos ao fato de que a narrativa é bem reflexiva e até mesmo nebulosa, especialmente quando fala de outros elementos que não dizem respeito ao Kris que narra a história. Logo, aqui há mais uma possibilidade investigação dos arquétipos em Solaris: tentar entender a relação dos arquétipos (hóspedes) diretamente com o inconsciente coletivo (oceano).

Seriam então os mimóides de Lem manifestações arquetípicas da mente humana e, a principal mensagem, a de que devemos compreendê-los para então sermos humanos mais realizados e resolvidos? Afinal, os mimóides são manifestações quase perfeitas, cópias que possuem tudo que um ser humano outrora teve em seu intelecto, mas ainda assim, são meras tentativas de reprodução imperfeitas em sua totalidade por não possuírem as nuances e detalhes que só uma verdadeira mente humana seria capaz de gerar.

No homem civilizado, o racionalismo da consciência (...) acaba sendo o maior obstáculo para que as transposições de energia fluam sem atrito. (...) A razão, porém, só é relativa e se anula a si mesma em suas antinomias. Ela também é apenas um meio para se atingir um fim uma expressão simbólica par ao ponto de transição de uma vida em desenvolvimento. (JUNG, 2012, p. 36)

Com essa citação de Jung podemos identificar que Kris Kelvin é um homem que busca as respostas em seu racionalismo de cientista sem perceber que ele mesmo está em atrito com suas próprias energias psíquicas. Energia psíquica, aqui, não é entendido como algo metafísico, mas como tudo que diz respeito a mente humana.

A partir da era moderna, um enredo carregado desses conteúdos arquétipos pode ser capaz de transmitir uma mensagem que signifique algo na vida de quem absorve a narrativa; através da mídia essas mensagens tornam-se significantes nas vidas de determinados grupos de pessoas. Afinal, "o primeiro narrador verdadeiro é e continua sendo o narrador de contos de fadas. Esse conto sabia dar um bom conselho, quando ele era difícil de obter, e oferecer ajuda, em caso de emergência" (BENJAMIN, 1987, p. 215). Ao falar do narrador do conto de fadas, Benjamin nos lembra das definições de literatura fantástica que, segundo Todorov refere-se a uma variedade de literatura, ou, como se diz comumente, a um gênero literário. Examinar obras literárias a partir da perspectiva de um 
gênero é um empreendimento absolutamente peculiar (TODOROV, 2010, p. 7). Ainda conclui que

O fantástico é a hesitação experimentada por um ser que só conhece as leis naturais, face a um acontecimento aparentemente sobrenatural. O conceito de fantástico se define, pois, com relação aos de real e imaginário: e estes últimos merecem mais do que uma simples menção (TODOROV, 2010, p. 31)

Kris Kelvin sempre é levado a sair de seu status quo devido às influências de outras pessoas, tenha sido em seu passado na Terra através da figura de Harey e do cientista Gibarian ou na estação através de Snaut e Sartorius. Desde sua chegada, ele foi impelido pelo destino para uma região desconhecida onde precisará passar por provações (CAMPBELL, 2007, p. 66) e no decorrer da trama esses chamados continuam até o desfecho onde ele decide por rumar em direção do oceano.

Simbolicamente, também é notório como os personagens da obra encarnam figuras arquetípicas oriundas do inconsciente coletivo. Aqui, pensando em "como o aspecto exterior e interior de uma única e mesma realidade [...] se esconde por trás das aparências" (JUNG, 2008, p. 352), encontramos relação a este pensamento proposto por Jung juntamente com a reflexão de Campbell (2007, p. 64) de que o desconhecido, surpreendente e até assustador inconsciente projeta o herói ou um personagem de encontro ao seu destino. Afinal, Kris precisa enfrentar seus demônios interiores e é impelido, pelo mundo inconsciente, a seguir um caminho. Em Solaris, o oceano vivo sempre é associado a figura de quem delimita o caminho dos cientistas e dita as regras: seja no ritmo do contato, seja em outros detalhes. A tentativa de bombardearem o oceano com raios a fim de acabar com essa interferência, subjetivamente pode ser encarado como o desejo de romper laços com o inconsciente coletivo e tornar-se um ser pleno de razão, coisa que a própria obra mostra ser falho. Sem as relações interpessoais, a tão elevada razão não possui, afinal, razão de ser.

Sobre narrativas, mais especificamente contos, Eliade diz que elas se repetem, em outro plano e através de outros meios. O conto reata e prolonga a "iniciação" ao nível do imaginário; aqui, lembremos de ritos primitivos de iniciação a fase adulta comuns em tribos para entender o que ele quis dizer com "iniciação". Eliade continua explicando sobre ao dizer que

Se ele representa um divertimento ou uma evasão, é apenas para a consciência banalizada e, particularmente, a consciência do homem 
moderno; na psique profunda, os enredos iniciatórios conservam sua seriedade e continuam a transmitir sua mensagem, a produzir mutação. Sem se dar conta e acreditando estar se divertindo ou se evadindo, o homem das sociedades modernas ainda se beneficia dessa iniciação imaginária proporcionada pelos contos. (ELIADE, 1986, p. 174).

Talvez possamos achar que Kris Kelvin já é um cientista e já foi “iniciado", podemos pensar nele como um ser que "superou o primitivo da nossa raça" e já está em uma fase "adulta", mas sua fragilidade perante para com o mundo é visível; não consegue lidar com dramas pessoais. Isso exemplifica justamente como ele tem algum problema para superar ou alguma iniciação pela qual passar. Vemos então que o ser humano precisa enfrentar uma constante superação de adversidades de relações com outros seres humanos ou de interpretações do que o mundo lhe expõe, ou seja, a as pessoas precisam entender a dinâmica da alteridade.

Se pensarmos na necessidade de entendermos uns aos outros não só como uma simples ideia, mas como um objetivo básico de comunicação da humanidade, podemos ver que as narrativas, não só em seus temas, mas estruturalmente já possuem como objetivo esse fim, pois "o propósito dramático do Herói é dar à plateia uma janela para a história. Cada pessoa (...) é convidada, nos estágios iniciais da história, a se identificar com o Herói, a se fundir com ele e ver o mundo por meio dos olhos dele" (VOGLER, 2006, p. 76).

Consciente ou inconscientemente (bem, sempre somos sujeitos ao inconsciente), Stanisław Lem fez de seu protagonista de Solaris justamente uma figura simbólica capaz de nos suscitar identificação. Como alguém que tem dificuldades em se encontrar, Kris Kelvin nos ajuda a refletir sobre nossas necessidades pessoais de superação. Joseph Campbell nos complementa essa ideia ao dizer que

Por essa necessidade de uma narrativa que introduza temas a psique que as pessoas são tão cativadas por essas histórias. E não temos uma única narrativa que sirva infinitamente à humanidade, mas sim várias atualizações em um ciclo permanente de renascimento, pois "dentro do espírito e do organismo social deve haver (...) uma contínua „recorrência de nascimento?" (CAMPBELL, 2007, p. 26)

Solaris, portanto, também é a atualização da narrativa arquetípica, tratou de temas que eram atuais ao período no qual foi escrito. Nessa liquidez, as pessoas são verdadeiros atores do cotidiano e outsiders para com outras culturas ou para com a sua própria, pois 
todos nós sabemos que somos seres materiais, submetidos às leis da fisiologia e da física, e que a força de todas nossas emoções reunidas não consegue lutar contra essas leis, mas apenas odiá-las (LEM, 2017, p. 309).

\section{CONCLUSÃO}

Foram exploradas várias reflexões, todas encaminhando para um conceito base, o da alteridade. Em Solaris, tudo é uma questão das relações e das dificuldades de compreensão mútua entre seres humanos e, ainda mais, com uma raça alienígena. Os arquétipos e a jornada do herói, por sua vez, evidenciaram que as narrativas versam, sobretudo, justamente sobre essa questão primordial de compreensão humana. No final, uma possibilidade de leitura para a jornada de Kris Kelvin seria a de que ele se anulou em suas antinomias; ele deveria atingir um fim com sua jornada, ou uma individuação como diria Jung. Com sua jornada, mas sem entender a expressão simbólica do inconsciente, Kris acabou por não conseguiu superar essa etapa de desenvolvimento de sua vida que deveria, num fim mais positivo, torná-lo mais pleno. Ou ainda, a suposta integração que ele faz com o oceano, no final da obra, seria justamente a sua união com o inconsciente. Isso é dito, pois "o herói, por conseguinte, é o homem ou mulher que conseguiu vencer suas limitações históricas pessoais e locais e alcançou formas normalmente válidas, humanas" (CAMPBELL, 2007, p. 28). Essas interpretações são algumas possíveis visões, mas a obra termina em aberto, pois "nesse sentido, mais do que nunca o que importa é o percurso percorrido, que se confunde com o objetivo em si; ou seja, o caminho é o único fim possível, apontando naturalmente para um recomeço" (CONTRERA, 1996, p. 112) ou ainda "o herói mitológico não é patrono das coisas que se tornaram, mas das coisas em processo de tornar-se" (CAMPBELL, 2007, p. 324).

Pelas teorias e ideias explanadas, é possível identificar que, como já dito, o oceano representaria a imensidão do inconsciente coletivo com o qual seres racionais acabam por se defrontar e, somente com a razão, não conseguem compreender. Harey, por sua vez, foi a sombra de Kris Kelvin durante seu percurso por Solaris. O psiquiatra teve que se defrontar com seu pesadelo interior, com a culpa que sentia pela morte da ex-parceira e teve que, mesmo que de uma forma "falsa", se reconciliar com a mesma. Ele precisava de uma segunda chance para enfrentar seu tormento interior e a obteve. Essa singular relação entre os dois, pode significar que o herói "descobre e assimila seu oposto (seu próprio eu insuspeitado), quer engolindo-o, quer sendo engolido por ele. (...) Então, descobre que 
seu oposto são, não de espécies diferentes, mas de uma mesma carne" (CAMPBELL, 2007, p. 110). A dualidade de um homem para com uma mulher também evidencia esse choque de opostos, conhecido da psicologia junguiana como anima e animus.

Para entendermos a sombra em detalhes, temos a seguinte definição do arquétipo:

O arquétipo conhecido como Sombra representa a energia do lado obscuro, os aspectos não-expressos, irrealizados ou rejeitados de alguma coisa. Muitas vezes, é onde moram os monstros reprimidos de nosso mundo interior. As sombras podem ser todas as coisas de que não gostamos em nós mesmos, todos segredos obscuros que não queremos admitir, nem para nós mesmos. As características a que renunciamos, ou que tentamos arrancar, ainda sobrevivem e agem no mundo das Sombras do inconsciente. A Sombra também pode abrigar qualidades positivas que estão ocultas ou que rejeitamos por um motivo qualquer (VOGLER, 2006, p. 123).

A personificação de Harey é, em determinado ponto da obra, apresentada justamente como uma leitura que o oceano fez da imagem dela que está nas memórias de Kris. Ou seja, Kris, afinal, estava defrontando a si mesmo ou sua sombra.

Solaris, afinal, é uma obra atemporal por ter um jogo complexo de reflexões humanas somadas a uma estrutura arquetípica intrínseca as demais obras criadas pela humanidade. Kris Kelvin é alguém que nos auxilia para que não tenhamos "de correr os riscos da aventura sozinhos; pois os heróis de todos os tempos nos precederam; o labirinto é totalmente conhecido" (CAMPBELL, 2007, p. 31). Graças a Stanisław Lem, temos uma obra que nos ajuda a enfrentarmos essa aventura de alteridade que é a vida humana. 


\section{REFERÊNCIAS:}

BAUMAN, Zygmunt. O mal-estar da pós-modernidade. Tradução de Mauro Gama e Cláudia Martinelli Gama. Rio de Janeiro: Zahar, 1997.

BENJAMIN, Walter. Magia e técnica, arte e política: Ensaios sobre literatura e história da cultura. Tradução de Sergio Paulo Rouanet. 3. ed. São Paulo: Brasiliense, 1987.

CAMPBELL, Joseph. O Herói de Mil Faces. Tradução de Adail Ubirajara. 11. reimpr. da $1^{a}$ ed. São Paulo: Cultrix/Pensamento, 2007.

CONTRERA, Malena Segura. O Mito na Mídia: A Presença de Conteúdos Arcaicos nos Meios de Comunicação. São Paulo: Annablume, 1996.

DICIO. Alteridade: Significado de Alteridade. Disponível em: $<$ https://www.dicio.com.br/alteridade/>. Acesso em 13 jun. 2019.

ELIADE, Mircea. Mito e Realidade. Tradução de Pola Civelli. 2. ed. São Paulo: Perspectiva, 1986.

ELIAS, Nobert. Os Estabelecidos e os Outsiders. Tradução de Vera Ribeiro. Rio de Janeiro: Zahar, 2000.

GOFFMAN, Erving. A Representação do Eu na Vida Cotidiana. Tradução de Maria Célia Santos Raposo. 7. ed. Petrópolis: Vozes, 1996.

GRAMONSKI, Fabiana. Lendo e traduzindo Solaris, entrevista com Eneida Favre. Quorpus, Florianópolis, n. 29, 2019. Disponível em: <http://qorpus.paginas.ufsc. br/\%E2\%80\%9C-a-procura-de-autor\%E2\%80\%9D/edicao-n-029/lendo-e-traduzindosolaris-entrevista-com-eneida-favre-por-fabiana-gramonski/>. Acesso em 16 maio 2019.

HOSCH, William L. Stanisław Lem: polish author. In: ENCYCLOPÆDIA Britannica. [S. 1.]: Encyclopædia Britannica. Disponível em: $<$ https://www.britannica.com/biography/Stanislaw-Lem>. Acesso em 05 jun. 2019.

JUNG, Carl Gustav. Energia Psíquica. Tradução de Pe. Dom Mateus Ramalho Rocha. 13. ed. Petrópolis: Vozes, 2012.

JUNG, Carl Gustav. Memórias, sonhos, reflexões. Tradução de Dora Ferreira da Silva. 16. ed. Rio de Janeiro: Nova Fronteira, 1994. 
JUNG, Carl Gustav. Os arquétipos e o inconsciente coletivo. Tradução de Dora Ferreira da Silva e Maria Luiza Appy. 2. ed. Rio de Janeiro: Vozes, 2000.

JUNG, Carl Gustav. O Desenvolvimento da Personalidade. Tradução de Frei Valdemar do Amaral. São Paulo: Círculo do Livro, 1995.

LEM about himself. Lem.pl. Stanisław Lem - The Official Site, c2016. Disponível em: $<$ https://english.lem.pl/index.php/home/biography/abouthimself $>$. Acesso em 05 jun. 2019.

LEM, Stanisław. Solaris. Tradução de Eneida Favre. São Paulo: ALEPH, 2017.

MARINO, Vinicius. Revisitando "Solaris": como o clássico de Lem mudou a literatura. 2017. Disponível em: <https:/www.finisgeekis.com/2017/04/19/revisitandosolaris-como-o-classico-de-lem-mudou-a-literatura/>. Acesso em 22 maio 2019.

PROPP, Vladimir I. Morfologia do Conto Maravilhoso. Tradução de Boris Schnaiderman. Rio de Janeiro: Forense Universitária, 2006.

TODOROV, Tzvetan. Introdução à literatura fantástica. Tradução de Maria Clara Correa Castello. 4. ed. São Paulo: Perspectiva, 2010.

VOGLER, Christopher. A Jornada do Escritor. Tradução de Ana Maria Machado. 2.ed. Rio de Janeiro: Nova Fronteira, 2006. 